\title{
A Systematic Analysis of Patient Portals Adoption, Acceptance and Usage: The Trajectory for Triple Aim?
}

\author{
Mohammad A. Al-Ramahi \\ Indiana University East \\ $\underline{\text { moaabdel@iu.edu }}$
}

\author{
Cherie Noteboom \\ Dakota State University \\ Cherie.Noteboom@dsu.edu
}

\begin{abstract}
Personal Health Records (PHR), often known as patient portal, are consumer-centric tools that can strengthen consumers' ability to actively manage their own health and healthcare. The incorporation of patient portals provides the promise to assist with Triple Aim and population health goals. Patient portals encourage patients to play a more active role in their healthcare by giving them more responsibility for maintaining a healthy lifestyle and managing chronic diseases and thus may provide a costeffective way to improve quality of care. In this study, we extend the existing literature by using a data analytic approach to provide more insights in adopting mobile patient portals.

Specifically, we aim to use topic modeling approach, LDA algorithm, to systematically analyze users' feedback (i.e., online users' reviews) from the actual use of a common mobile patient portal, Epic's MyChart. To validate the extracted topics, we compared the results of $L D A$ analysis with that of human analysis. Overall, the extracted topics revealed opportunities for improvement and to enhance the design of current basic portals to improve usage. Improved portal usage will move toward effective population health management and achievement of the triple aim goals.
\end{abstract}

\section{Introduction}

"The nation's expenditures for health care, already the highest among developed countries, are expected to rise considerably as chronic diseases affect growing numbers of older adults. Today, more than two-thirds of all health care costs are for treating chronic illnesses. Among health care costs for older Americans, 95\% are for chronic diseases. The cost of providing health care for one person aged 65 or older is three to five times higher than the cost for someone younger than 65.7. By 2030, health care spending will increase by $25 \%$, largely because the population will be older" [1]. In fact, the United States spends 17.4 percent of its GDP on health care, more than any other country in the world [2]. Despite this \$2.9 trillion expenditure, the quality and efficiency of the U.S. health care system ranks last when compared to Australia, Canada, France, Germany, the Netherlands, New Zealand, Norway, Sweden, Switzerland, and the United Kingdom [3]. As a result, a concerted national effort to reform health care using information technology (IT) with a focus on reducing costs and increasing quality of service is well under way [2].

In this regard, the Triple Aim is defined by the Institute for Healthcare Improvement (IHI) as the ability to simultaneously deliver excellent quality, at optimized costs, while improving the health of the population. Population health could be defined as "the health outcomes of a group of individuals, including the distribution of such outcomes within the group" [4]. The ability to achieve the triple aim goals will be a major contributor to U.S. healthcare transformation. Healthcare costs, quality challenge and population health statistics indicate a need for attention as population demographics change [1, 5]. According to CDCP [1], "More than a quarter of all Americans and two out of every three older Americans have multiple chronic conditions, and treatment for this population accounts for $66 \%$ of the country's health care budget". Successfully achieving the triple aim is likely to contribute to high performing healthcare systems.

To address each of the components of the triple aim and achieve the goals of improving care, reducing cost and improving population health, Health Information Technology (HIT) is necessary tool. More importantly, IT can facilitate costeffective communication and collaboration between patients and health professionals, and it can empower patients to take an active role in improving their health outcomes by, for example, monitoring health conditions $[6,7]$. 
Personal Health Records (PHR), often known as patient portal, are consumer-centric tools that can strengthen consumers' ability and behavior to actively manage their own health and healthcare. The capabilities generally capture information about an individual's diagnoses, medications, allergies, lab test results, immunization records and other personal health information. In addition, patient portals provide convenience tools to provide appointment functionality, prescription support and billing features, and Communication tools can assist connecting to various health care professionals [8].

The incorporation of patient portals provides the promise to assist with Triple Aim and population health goals. Prgomet, et al. [9] conducted a systematic review identified ability of mobile technology to positively impact error prevention, information accessibility and data management in healthcare settings. Patient portals encourage patients to play a more active role in their healthcare by giving them more responsibility for maintaining a healthy lifestyle and managing chronic diseases and thus may provide a cost-effective way to improve quality of care [10].

According to CDW [5]'s report, Patient Engagement Perspectives Key Findings, people using online patient portals grew from $45 \%$ in 2016 to $74 \%$ of patients in 2017 . In addition, the commonly held belief that older patients won't want or be able to access their online health information is proving to be a fallacy. By 2017, 53 percent of older patients over 50 years of age said they used a portal at least monthly [11]. 83 percent of patients are comfortable communicating with providers via mobile apps [11].

A study of more than 200 healthcare provider employees found that nearly 90 percent of respondents are utilizing mobile devices within their organizations to engage patients in their healthcare. The respondents believe that mHealth technologies are beginning to drive cost savings and improve the quality of care delivered which in turn help meet the triple aim goals [12]. Respondents reported leveraging a variety of mobile tools including appenabled patient portals (73 percent). 36 percent of respondents believe the use of app-enabled patient portals is the most effective tool in patient engagement to date [12].

Despite its potential benefits and growing popularity, patient portals still have not been used to their fullest strength. Sadly, only 29 percent of patients would give their healthcare providers an " $A$ " for their use of technology to engage with them [13]. The bottom line: nine in 10 patients would like to be able to more easily access their personal healthcare records [13]. Developing patient portals that offer innovative user experiences is a challenging task. By definition, the concept of innovating with user experience goes beyond developing patient portals that merely satisfy users' expectations of technology. Instead, portals must provide unexpectedly meaningful and delightful user experiences [14, 15].

Past technology research [e.g., 16, 17, 18] has investigated collaboration effects and provides insight to inform the patient portal research in the areas of collaboration, coordination, communication and adaptation. In addition, the adaptation insights at the work, social, and technology levels inform this research. However, existing studies have mainly relied on survey-based approaches to capture behavioral intent of accepting or using the patient portal. User behavior with systems is too complex to be understood from subjective measures alone. With advances in monitoring system use and data analytics, newer approaches that track and analyze user actual behavior with system can provide a much better indicator of systems' acceptance and use. Therefore, studies that systematically analyzing users' feedback gathered from the electronic wordof-mouth (eWOM) are needed to better understand the adoption and usage of patient portals. Nowadays, the advances of Web 2.0 technologies have enabled consumers to easily and freely exchange opinions on products and services on an unprecedented scale (volume) and in real time (velocity). Online user review systems provide us with one of the most powerful channels for extracting user feedback that can help enhance Health Information Technology (HIT) design. In the e-commerce domain, users reviews have long been widely recognized as a crucial factor that influences products sales [e.g., 19] and shapes consumers' purchase intention [e.g., 20]. In the domain of patient portals, analyzing users' reviews has the potential to greatly inform developers about how patients engage with portals and opportunities for further enhancing their efficacy to achieve the triple aim goals.

In this study, we answer the call for studies that advance the use of analytics approaches for understanding IT usage by investigating the key dimensions relating to the use of mobile patient portals as mHealth technologies via systematically analyze users' reviews of patient portal mobile apps. We use MyChart reviews as Epic has captured significant market share with at least partial health information for $51 \%$ of the US population. It has been described as the default EHR choice not for its superior performance but because other systems are considered inferior [21]. Given the huge amounts of mobile apps reviews data available and to facilitate the analysis process, we utilizes a text-mining 
approach proposed by Al-Ramahi, et al. [22] to automatically analyze the contents of user reviews.

\section{Related Work \& Background}

\subsection{Mobile Health (mHealth)}

With the exponential growth of the communications technologies that allow us to potentially reach more individuals regardless of their locations, new types of health intervention emerged. Smartphone or mobile-based health apps can enhance patients' engagement at a very low cost. While the results of Health Information Technology (HIT) use by providers are mixed, it appears that motivated patients can achieve significant improvements in their health outcomes when they use mobile applications [23].

Due to the promising influence of these smartphone-based technologies in supporting healthy lifestyle and self-care practices, researchers have been inspired to explore the impact and use of mobile applications. For example, the fact that women widely used mobile apps for health information during pregnancy, but reported apps as unavailable or invaluable postpartum, highlights the need for the development of more mobile apps with postpartum content [24]. With this respect, Zhang, et al. [25]'s study is one of the first few studies to describe the methodology of developing an online and smartphone compatible cognitive behavioral therapy intervention program for bariatric surgery patients. In fact, the potential benefits of the smartphones and healthcare apps are recognized by healthcare professionals [26]. Mobile health has been used as a tool to support patient management of chronic diseases including type 2 diabetes mellitus [27], hypertension [e.g., 28, 29] and sickle cell disease [30].

\subsection{Mobile Personal Health Records (m- PHRs)/Mobile Patient Portal}

Little attention, however, has been paid to leveraging mobile health technologies for risk management for disease prevention [31]. In this regard, Mobile PHRs (m-PHRs) that use a smartphone or tablet device have also been developed to provide more accessibility and mobility for patients' health. m-PHR could be the hub of m-health because it contains patient health information is in the hands of the patients themselves, and can be directly connected to peripheral devices such as activity trackers and blood sugar test devices [32].
m-PHR, therefore, have the potential to better inform and engage patients in their care. Healthcare providers feel the information provided by patient portal helps facilitate patient engagement in care and identification of errors [33]. Little research, however, has been done to connect the growing mobile application use by patients to accessing their healthcare data. The focus of previous studies included providing access to the patient record and information on the care team through a mobile phone app [e.g., 34], a tablet computer app to view care team profiles and hospital medication records, and a tablet app with the plan of care, diet and safety information [35]. Providing patients real-time access to health information has been demonstrated as a positive force for change in the way care is provided [36]. In this regard, Lu, et al. [37] develop an App to inspect controlled substances in patient care units. Using a web-enabled smartphone, pharmacist inspection can be performed on site and the inspection results can be directly recorded into the HIS through the Internet so human error of data translation can be minimized and the work efficiency and data processing can be improved.

While previous studies reported positive findings, including patient reports of enhanced engagement in the care process and satisfaction with care, none included patient-centered functionality such as the ability to send messages to the care team, allowing patients to input information or record noteselements that have been demonstrated to further enhance patients' engagement [36]. This is especially true with the proliferation of wearable devices, where data about an individual's health state can be collected by real-time sampling and analysis of a few parameters using noninvasive, inexpensive, and portable devices [38]. With this respect, Neubeck, et al. [39] adopted a collaborative user-centered design process to develop a patient-centered e-health tool. O'Leary, et al. [33] concluded that optimizing a hospital-based patient portal will require attention to type, timing and format of information provided, as well as the impact on patient-provider communication and workflow. Patients can identify areas of improvement that could enhance the design of portals. For example, patients suggested inclusion of a test result feature [33]. Therefore, further research is needed to work in concert with patients to explore patient-centered functionalities that help develop a patient-centric portal to increase patients' engagement in their care.

Leveraging user feedback from the actual use of mobile patient portal, this research contributes to an understanding of how the technology architecture can enable patients to interact with patient portal 
functionality, which is technological adaptation, to work (work adaptation) together with their physicians and care providers (social adaptation) using the content available to them and using the collaboration media to provide patient centered care.

\section{Method}

This section describes the methodology used to systematically analyze the online users reviews of mobile patient portal. Figure 1. shows the framework of the text mining-based method, which is adopted from [22]. We propose to use an unsupervised topic model, Latent Dirichlet Allocation (LDA), to extract latent dimensions (i.e. hidden topics) from usergenerated data. Below, we first discuss the data collection and preparation process. We then explain the topic modeling technique used to extract insights from users' feedback.

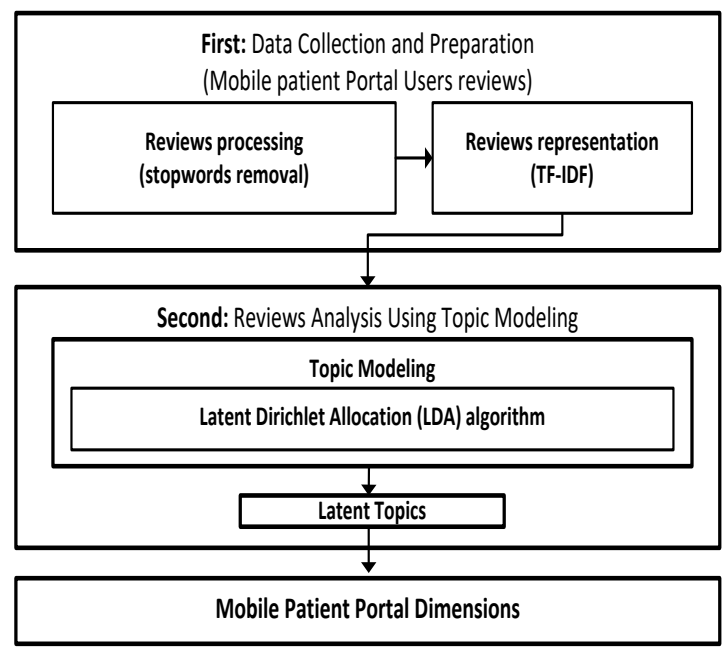

Figure 1. Architecture of our text mining-based

method [22]

\subsection{Data Collection and Preparation}

In this study, our target population is mobile patient portal users. The patient portal selected as empirical setting of this research is Epic's MyChart. We selected this patient portal for study as Epic is replacing other vendors in the EHR market and is beginning to establish a single vendor landscape. Reportedly, Epic has at least partial health information for over $51 \%$ of the US population [21]. MyChart mobile app is available for Apple and Android devices. The data was collected from Apple iTunes store, where the online reviews posted by the users were gathered using the Apple store API. We developed a web crawler to automatically collect data. Through this process, we obtain our data set consisting of 500 reviews. When preprocessing the data, we removed stop words and represented each document using the well-known Term Frequency Inverse Document Frequency (TF-IDF) weighting scheme [40]. Specifically, TF-IDF weight of a word $i$ in a document $j$ is given by

$$
F_{\mathrm{i}_{j} j} * \log (N / D F)
$$

Where $F_{i, j}$ is the frequency of the word $i$ in the document $j, \mathrm{~N}$ indicates the number of documents in the corpus, and DF is the number of documents that contains word $i$.

\subsection{Topic Modeling: LDA}

Topic models are statistical-based algorithms for discovering the main themes (i.e. set of topics) that describe a large and unstructured collection of documents. Topic models allow us to summarize textual data at a scale that is impossible to be tackled by human annotation. We selected the Latent Dirichlet Allocation (LDA) model, the most common topic model currently in use, due to its conceptual advantage over other latent topic models [41]. The model generates automatic summaries of topics in terms of a discrete probability distribution over words for each topic, and it also infers per-document discrete distributions over topics. The interaction between the observed documents and hidden topic structure is manifested in the probabilistic generative process associated with LDA. This generative process can be thought of as a random process that is assumed to have produced the observed document [42]. To illustrate the results of LDA, Let $M, K, N$, and $V$ be the number of documents in a collection, the number of topics, the number of words in a document, and the vocabulary size, respectively. The first result is an $M \times K$ matrix, where the weight $w_{m, k}$ is the association between a document $d_{m}$ and a topic $t_{k}$. In our case, the documents are user reviews for patient portal MyChart app (i.e. we integrated the reviews of the app in a data file and treated each user review as a single document) $(M=500)$. The second result is an $N \times K$ matrix, where the weight $w_{n, k}$ is the association between a word $w_{n}$ and a topic $t_{k}$. The notations Dirichlet(·) and Multinomial(·) represent Dirichlet and multinomial distribution with parameter $(\cdot)$ respectively. The graphical representation of LDA is shown in Figure 2, and the corresponding generative process is shown below:

(1) For each topic $\mathrm{t} \in\{1, \ldots, K\}$,

(a) draw a distribution over vocabulary words $\beta_{t} \sim \operatorname{Dirichlet}(\eta)$ 
(2) For each document d,

(a) draw a vector of topic proportions $\theta_{d} \sim \operatorname{Dirichlet}(\alpha)$.

(b) For each word $w_{n}$ in document d, where $n \in\{1, \ldots, N\}$,

(i) draw a topic assignment $\mathrm{z}_{\mathrm{n}} \sim \operatorname{Multinomial}\left(\theta_{\mathrm{d}}\right)$

(ii) draw a word $w_{n} \sim \operatorname{Multinomial}\left(\beta_{z n}\right)$.

The notation $\beta_{t}$ is the $V$-dimensional word distribution for topic $t$, and $\theta_{d}$ is the $K$-dimensional topic proportion for document $d$. The notations $\eta$ and $\alpha$ represent the hyperparameters of the corresponding Dirichlet distributions.

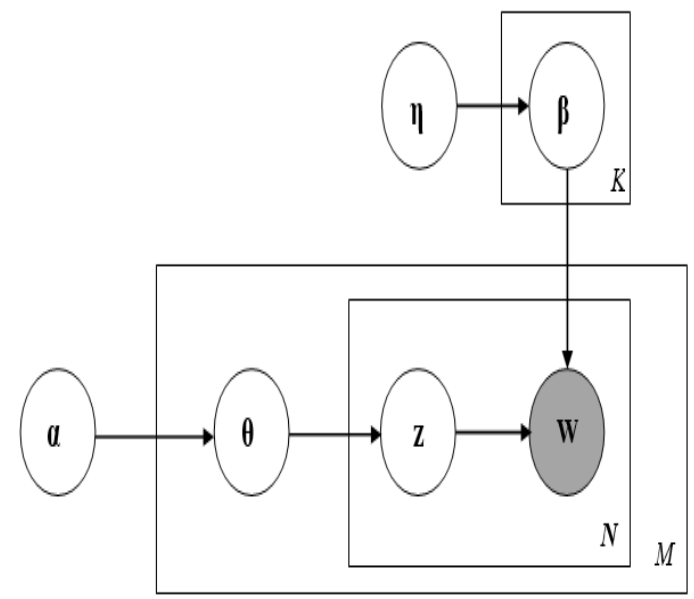

Figure 2. Graphical model of LDA

\section{Results}

In this section, we summarize the results of the extraction of the topics from users feedback using LDA analysis. We then examine the validity of these topics by comparing them with the results of human analysis.

\subsection{Topics Extracted}

Table 1 presents the 25 topics learned by our LDA model along with the assigned labels. Within each topic showed the top-10 words and their relative weight. The labeling of topics was first conducted by the first author and confirmed by the second author. Labeling was initially based on the identification of a logical connection between these 10 most frequent words for a topic. For example, in Table 1, the topic name "Sync with health apps" is based on the word 'sync', weighted $0.6 \%$, 'app' weighted $0.7 \%$, and 'health', weighted $0.7 \%$. Once specified, a candidate topic label was then further tested via investigating the reviews that are highly associated with that topic.

Table 1: Topics extracted using LDA

\begin{tabular}{|c|c|}
\hline Topic & Top-10 words with weights \\
\hline T1: Notifications & $\begin{array}{l}0.007 * \text { ios, } 0.007 * \text { app } \\
0.006 * \text { option, } \\
0.006 * \text { notifications, } \\
0.005 * \text { town, } 0.005 * \text { mychart, } \\
0.005 * \text { health, } 0.005 * \text { small, } \\
0.004 * \text { recently, } 0.004 * \text { reason }\end{array}$ \\
\hline T2: Touch id & $\begin{array}{l}0.010 * \text { touch, } 0.010 * \text { id, } \\
0.007 * \text { password, } 0.007 * \text { app } \\
0.007 * \text { good, } 0.006 * \text { like, } \\
0.006 * \text { support }, 0.006 * \text { new } \\
0.006 * \text { pretty, } 0.005 * \text { available }\end{array}$ \\
\hline $\begin{array}{l}\text { T3: Send } \\
\text { messages }\end{array}$ & $\begin{array}{l}0.012 * \text { app }, 0.008 * \text { feature, } \\
0.007 * \text { message, } \\
0.007 * \text { information, } \\
0.006 * \text { office, } 0.006 * \text { sent, } \\
0.005 * \text { schedule, } 0.005 * \text { new, } \\
0.005 * \text { messages, } 0.005 * \text { love }\end{array}$ \\
\hline T4: Update data & $\begin{array}{l}0.017 * \operatorname{login}, 0.014 * \text { update, } \\
0.011 * \text { app, } 0.009 * \text { data, } \\
0.008 * \text { right, } 0.006 * \text { account, } \\
0.006 * \text { xe, } 0.006 * \text { error, } \\
0.006 * \text { away, } 0.006 * \text { latest }\end{array}$ \\
\hline $\begin{array}{l}\text { T5: Visit } \\
\text { summaries }\end{array}$ & $\begin{array}{l}0.009 * \text { app }, 0.006 * \mathrm{msg}, \\
0.006 * \text { use, } 0.005 * \text { logon, } \\
0.005 * \text { innovative, } \\
0.005 * \text { practical, } 0.005 * \text { update, } \\
0.005 * \text { password, } 0.005 * \text { visit, } \\
0.005 * \text { summaries }\end{array}$ \\
\hline $\begin{array}{l}\text { T6: Sync with } \\
\text { health apps }\end{array}$ & $\begin{array}{l}0.007 * \text { app, } 0.007 * \text { manage } \\
0.007 * \text { health }, 0.006 * \text { sync, } \\
0.006 * \text { ipad, } 0.006 * \text { push, } \\
0.006 * \text { love }, 0.005 * \text { care } \\
0.005 * \text { point, } 0.005 * \text { password }\end{array}$ \\
\hline T7: Fix app fast & $\begin{array}{l}0.013 * \text { fix }, 0.010 * \text { app } \\
0.009 * \text { update, } 0.008 * \text { crap, } \\
0.007 * \text { open, } 0.006 * \text { completely, } \\
0.005 * \text { fast, } 0.005 * \text { health } \\
0.005 * \text { tried, } 0.005 * \text { plz }\end{array}$ \\
\hline $\begin{array}{l}\text { T8: } \\
\text { Appointments }\end{array}$ & $\begin{array}{l}\text { 0.014*says, } 0.013 * \text { app } \\
0.010 * \text { available, } \\
0.009 * \text { appointments, } \\
0.009 * \text { chart, } 0.008 * \text { wish, } \\
0.008 * \text { great, } 0.007 * \text { able, } \\
0.007 * \text { information, } 0.007 * \text { like }\end{array}$ \\
\hline $\begin{array}{l}\text { T9: } \\
\text { Appointments }\end{array}$ & $\begin{array}{l}0.011 * \text { app, } 0.006 * \text { able } \\
0.006 * \text { option, } 0.006 * \text { work } \\
0.006 * \text { make, } 0.006 * \log , \\
0.006 * \text { appointments, } \\
\text { 0.005*providers, } \\
\text { 0.005*appointment, }\end{array}$ \\
\hline
\end{tabular}




\begin{tabular}{|c|c|}
\hline & $0.005 *$ making \\
\hline $\begin{array}{l}\text { T10: Server } \\
\text { connecting } \\
\text { problems }\end{array}$ & $\begin{array}{l}0.020 * \text { server, } 0.013 * \text { problem, } \\
0.012 * \text { connect, } 0.012 * \text { saying, } \\
0.011 * \text { keeps, } 0.011 * \text { fix } \\
0.009 * \text { communicating, } \\
0.009 * \text { app, } 0.009 * \text { worked, } \\
0.009 * \text { later }\end{array}$ \\
\hline $\begin{array}{l}\text { T11: } \\
\text { Communication } \\
\text { with doctors }\end{array}$ & $\begin{array}{l}0.015 * \text { app }, 0.011 * \text { messages, } \\
0.010 * \text { doctors, } 0.010 * \text { doctor, } \\
0.009 * \text { medical, } 0.009 * \text { great, } \\
0.008 * \text { love, } 0.008 * \text { send, } \\
0.008 * \text { use, } 0.008 * \text { communicate }\end{array}$ \\
\hline $\begin{array}{l}\text { T12: } \log \text { in } \\
\text { using touch id }\end{array}$ & $\begin{array}{l}\text { 0.012*app, } 0.008 * \text { touch, } \\
0.008 * \text { id, } 0.007 * \text { health, } \\
0.006 * \text { medical }, 0.005 * \text { account, } \\
0.005 * \text { apple, } 0.005 * \log , \\
0.005 * \text { xe, } 0.005 * \text { lets }\end{array}$ \\
\hline $\begin{array}{l}\text { T13: User } \\
\text { friendly app }\end{array}$ & $\begin{array}{l}0.016 * \log , 0.014 * \text { app }, \\
0.010 * \text { ability, } 0.007 * \text { user, } \\
0.007 * \text { health, } 0.007 * \text { make, } \\
0.007 * \text { friendly, } 0.007 * \text { nice, } \\
0.007 * \text { needs, } 0.006 * \text { load }\end{array}$ \\
\hline T14: ipad version & $\begin{array}{l}\text { 0.012*ipad, } 0.011 * \text { updated, } \\
0.010 * \text { needs, } 0.008 * \text { way, } \\
0.008 * \text { app, } 0.006 * \text { version, } \\
0.006 * \text { work, } 0.005 * \text { especially, } \\
0.005 * \text { ihealth, } 0.005 * \text { fixed }\end{array}$ \\
\hline $\begin{array}{l}\text { T15: } \\
\text { Appointments } \\
\text { schedule }\end{array}$ & $\begin{array}{l}0.013 * \text { app, } 0.008 * \text { use, } \\
0.007 * \text { called }, 0.006 * \text { update, } \\
0.005 * \text { doctor, } 0.005 * \text { schedule, } \\
0.005 * \text { star, } 0.005 * \text { care, } \\
0.005 * \text { appointments, } \\
0.005 * \text { really }\end{array}$ \\
\hline $\begin{array}{l}\text { T16: View letters } \\
\text { and messages } \\
\text { from doctors }\end{array}$ & $\begin{array}{l}0.011 * \text { like }, 0.008 * \text { letters, } \\
0.007 * \text { organized, } 0.007 * \text { view, } \\
0.007 * \text { doctors, } \\
0.006 * \text { messages, } \\
0.006 * \text { password, } 0.006 * \text { love, } \\
0.006 * \text { use, } 0.005 * \text { update } \\
\end{array}$ \\
\hline $\begin{array}{l}\text { T17: App needs } \\
\text { fix }\end{array}$ & $\begin{array}{l}0.012 * \text { app, } 0.007 * \text { new, } \\
0.007 * \text { let, } 0.006 * \text { read, } \\
0.006 * \text { time, } 0.006 * \text { happy, } \\
0.006 * \text { change, } 0.005 * \text { needs, } \\
0.005 * \text { fix, } 0.005 * \text { pls }\end{array}$ \\
\hline $\begin{array}{l}\text { T18: Access } \\
\text { results }\end{array}$ & $\begin{array}{l}0.010 * \log , 0.009 * \text { app } \\
0.008 * \text { mychart, } 0.006 * \text { safari, } \\
0.006 * \text { unable, } 0.006 * \text { hospital, } \\
0.005 * \text { provider, } 0.005 * \text { access, } \\
0.005 * \text { phone, } 0.005 * \text { results }\end{array}$ \\
\hline T19: Touch id & $\begin{array}{l}0.008 * \text { app }, 0.008 * \text { months, } \\
0.007 * \text { setting, } 0.006 * \text { card, } \\
0.005 * \text { able, } 0.005 * \text { id, } \\
0.005 * \text { everytime, } 0.005 * \text { touch, } \\
0.005 * \text { using, } 0.005 * \text { option }\end{array}$ \\
\hline
\end{tabular}

\begin{tabular}{|c|c|}
\hline $\begin{array}{l}\text { T20: Push } \\
\text { notifications }\end{array}$ & $\begin{array}{l}0.010 * \text { version, } 0.007 * \text { like, } \\
0.007 * \text { love }, 0.006 * \text { using } \\
0.006 * \text { push, } 0.006 * \text { app } \\
0.006 * \text { need, } 0.006 * \text { apple, } \\
0.006 * \text { use, } 0.005 * \text { older }\end{array}$ \\
\hline $\begin{array}{l}\text { T21: } \\
\text { Appointments }\end{array}$ & $\begin{array}{l}0.009 * \text { good, } \\
0.009 * \text { appointment, } 0.008 * \text { app, } \\
0.005 * \text { shuts, } 0.005 * \text { website, } \\
0.005 * \text { record }, 0.005 * \text { onpatient, } \\
0.004 * \text { sooner, } 0.004 * \text { document, } \\
0.004 * \text { looked }\end{array}$ \\
\hline $\begin{array}{l}\text { T22: } \\
\text { Notifications }\end{array}$ & $\begin{array}{l}0.008 * \text { like, } 0.007 * \text { notifications, } \\
0.006 * \text { doctor, } 0.006 * \text { update, } \\
0.006 * \text { medical, } 0.006 * \text { provider, } \\
0.006 * \text { app, } 0.006 * \text { good, } \\
0.006 * \text { fix, } 0.005 * \text { resolution }\end{array}$ \\
\hline $\begin{array}{l}\text { T23: Send } \\
\text { messages }\end{array}$ & $\begin{array}{l}0.011 * \text { conditions, } 0.011 * \text { terms, } \\
0.010 * \text { app, } 0.007 * \text { message, } \\
0.007 * \text { sent }, 0.007 * \text { login, } \\
0.007 * \text { loaded }, 0.007 * \text { warning, } \\
0.006 * \text { people, } 0.006 * \text { work }\end{array}$ \\
\hline $\begin{array}{l}\text { T24: View test } \\
\text { results }\end{array}$ & $\begin{array}{l}0.014 * \text { results, } 0.010 * \text { test, } \\
0.008 * \text { use, } 0.007 * \text { computer, } \\
0.007 * \text { appointments, } \\
0.006 * \text { app, } 0.006 * \text { nice, } \\
0.006 * \text { browser }, 0.005 * \text { doctor, } \\
0.005 * \text { view }\end{array}$ \\
\hline $\begin{array}{l}\text { T25: Email } \\
\text { health providers }\end{array}$ & $\begin{array}{l}0.006 * \text { touch, } 0.006 * \text { write, } \\
0.006 * \text { gone, } 0.005 * \text { providers, } \\
0.005 * \text { app, } 0.005 * \text { emails, } \\
0.005 * \text { health, } 0.005 * \text { setup, } \\
0.005 * \text { soon, } 0.004 * \text { activating }\end{array}$ \\
\hline
\end{tabular}

To remove redundancy in topics obtained (i.e., T8, T9, T15, T21) and to aggregate related topics into a higher level dimension, the topics obtained were then mapped into 11 dimensions shown in Table 2. For example, technical problems-related topics ("Fix app fast", "Server connecting problems", and "App needs fix") were mapped to the "Technical problems" dimension. The "Send messages", "Communication with doctors", "View letters and messages from doctors", and "Email health providers" topics that are related to communication with doctors were mapped to "Communication with health providers".

Table 2: Dimensions of users' experiences

\begin{tabular}{|l|l|}
\hline \multicolumn{1}{|c|}{ Dimension } & $\begin{array}{l}\text { Examples from users } \\
\text { feedback }\end{array}$ \\
\hline Push notifications & $\begin{array}{l}\text { - Useless if not notified of } \\
\text { the important messages } \\
\text { received within the app. }\end{array}$ \\
& $\begin{array}{l}\text { - I can't believe that there } \\
\text { has been another update and } \\
\text { still no push notifications! }\end{array}$ \\
\hline
\end{tabular}




\begin{tabular}{|c|c|}
\hline $\begin{array}{l}\text { Log in using touch id } \\
{[\mathrm{T} 2, \mathrm{~T} 12, \mathrm{~T} 19]}\end{array}$ & $\begin{array}{l}\text { - I would really like Touch } \\
\text { ID support for logging into } \\
\text { my provider instead of } \\
\text { entering my password every } \\
\text { time. } \\
\text { - I liked the app before and } \\
\text { would had given it } 4-5 \text { stars } \\
\text { with successful integration } \\
\text { of the TouchID feature. }\end{array}$ \\
\hline $\begin{array}{l}\text { Communication with } \\
\text { health providers [T3, } \\
\mathrm{T} 11, \mathrm{~T} 16, \mathrm{~T} 23, \mathrm{~T} 25]\end{array}$ & $\begin{array}{l}\text { - No ability to send } \\
\text { messages to your doctor } \\
\text { with any kind of } \\
\text { attachment. } \\
\text { - There is no record of the } \\
\text { messages I send to my } \\
\text { provider unless they reply. } \\
\text { - There is no option to view } \\
\text { any letters that doctors } \\
\text { uploaded. }\end{array}$ \\
\hline $\begin{array}{l}\text { Update medical data } \\
\text { [T4] }\end{array}$ & $\begin{array}{l}\text { - Giving us ability to update } \\
\text { vaccines would be } \\
\text { appreciated. } \\
\text { - So it be great if I could } \\
\text { update my shots and other } \\
\text { medical issues. } \\
\text { - Gives no ability to } \\
\text { patient/user } \\
\text { correct/update data. Have to } \\
\text { request medical personnel } \\
\text { to make changes, which in } \\
\text { my case they often don't do. }\end{array}$ \\
\hline $\begin{array}{l}\text { Medical summaries } \\
\text { (data to knowledge } \\
\text { presentation) }[\mathrm{T} 5]\end{array}$ & $\begin{array}{l}\text { - It's already bad enough } \\
\text { that I can't access ER } \\
\text { summaries on the app. } \\
\text { - The computer based app } \\
\text { allows you to see the office } \\
\text { visit summaries but that is } \\
\text { missing that feature. } \\
\text { - I am able to get medical } \\
\text { summaries. } \\
\text { - This app is a perfect } \\
\text { summary of all of my health } \\
\text { issues. }\end{array}$ \\
\hline $\begin{array}{l}\text { Integration with } \\
\text { health apps [T6] }\end{array}$ & $\begin{array}{l}\text { - No sync with Apple } \\
\text { Health. Without that, what } \\
\text { is the point. } \\
\text { - Completely outdated and } \\
\text { lacks important features } \\
\text { such as apple health app } \\
\text { integration. } \\
\text { - I should be able to export } \\
\text { the relevant data straight to } \\
\text { the Health app. }\end{array}$ \\
\hline $\begin{array}{l}\text { Appointments } \quad[\mathrm{T} 8, \\
\text { T9, T15, T21] }\end{array}$ & $\begin{array}{l}\text { - I once was able to request } \\
\text {; schedule appointments but }\end{array}$ \\
\hline
\end{tabular}

\begin{tabular}{|l|l|}
\hline & $\begin{array}{l}\text { I no longer have that } \\
\text { capability. } \\
- \text { Still can't make } \\
\text { appointments. }\end{array}$ \\
\hline $\begin{array}{l}\text { Technical problems } \\
\text { [T7, T10, T17] }\end{array}$ & $\begin{array}{l}\text { - it can't communicate with } \\
\text { the server. } \\
- \text { I get a server error } \\
\text { whenever I open the app. } \\
\text { Works fine in a browser. } \\
\text { Please fix. }\end{array}$ \\
\hline $\begin{array}{l}\text { User friendly app } \\
\text { [T13] }\end{array}$ & $\begin{array}{l}\text { - Very user friendly to me. I } \\
\text { really like it. }\end{array}$ \\
\hline ipad version [T14] & $\begin{array}{l}\text { - I use MyChart on both my } \\
\text { iPhone and iPad. } \\
\text { - This would be a good app } \\
\text { if worked on the iPad in } \\
\text { Landscape mode. }\end{array}$ \\
\hline $\begin{array}{l}\text { Access and view } \\
\text { data [T18, T24] }\end{array}$ & $\begin{array}{l}\text { - There is extremely limited } \\
\text { access to your records and } \\
\text { information. } \\
\text { - One of the benefits is to be } \\
\text { able to access your health } \\
\text { information from any } \\
\text { location and this has not } \\
\text { been the case for me. } \\
- \text { Does not allow you to } \\
\text { view scanned lab results }\end{array}$ \\
\hline
\end{tabular}

\subsection{Validity of Dimensions Discovered}

We examined the validity of the extracted dimensions by comparing the results of LDA analysis with that of human analysis (see Table 3 ). To conduct the manual analysis, we adopted open coding technique for data analysis. Two independent researchers read the collected reviews and then identify the dimensions mentioned in these reviews. We compared the dimensions derived from the LDA analysis with the ones identified by the two researchers to calculate the reliability of the LDA result. The Jaccard coefficient ${ }^{1}$ is 0.73 and 0.67 between the automated analysis and the two researchers, A and B respectively. As shown in Table 3 , the manual coding of the data revealed four new dimensions: "Export/Import data" that refers to export and save health data to files, "Support multiple health providers" which is related to support more than one health provider, "Technical support" and "Billing issues".

\footnotetext{
1 The Jaccard coefficient measures similarity between finite sample sets, and is defined as the size of the intersection divided by the size of the union of the sample sets.
} 
Table 3: A comparison of dimensions between LDA analysis and human analysis

\begin{tabular}{|l|l|l|l|}
\hline Dimension & $\begin{array}{l}\text { LDA } \\
\text { analysis }\end{array}$ & $\begin{array}{l}\text { Resear- } \\
\text { cher A }\end{array}$ & $\begin{array}{l}\text { Resear- } \\
\text { cher B }\end{array}$ \\
\hline Appointments & $\sqrt{ }$ & $\sqrt{ }$ & $\sqrt{ }$ \\
\hline $\begin{array}{l}\text { Push } \\
\text { notifications }\end{array}$ & $\sqrt{ }$ & $\sqrt{ }$ & $\sqrt{ }$ \\
\hline $\begin{array}{l}\text { Integration with } \\
\text { health apps }\end{array}$ & $\sqrt{ }$ & $\sqrt{ }$ & $\sqrt{ }$ \\
\hline $\begin{array}{l}\text { Communication } \\
\text { with health } \\
\text { providers }\end{array}$ & $\sqrt{ }$ & $\sqrt{ }$ & $\sqrt{ }$ \\
\hline $\begin{array}{l}\text { Log in using } \\
\text { touch id }\end{array}$ & $\sqrt{ }$ & $\sqrt{ }$ & $\sqrt{ }$ \\
\hline $\begin{array}{l}\text { Access and view } \\
\text { data }\end{array}$ & $\sqrt{ }$ & $\sqrt{ }$ & $\sqrt{ }$ \\
\hline $\begin{array}{l}\text { Medical } \\
\text { summaries } \\
\text { (data to } \\
\text { knowledge } \\
\text { presentation) }\end{array}$ & $\sqrt{ }$ & $\sqrt{ }$ & $\sqrt{ }$ \\
\hline $\begin{array}{l}\text { Update medical } \\
\text { data }\end{array}$ & $\sqrt{ }$ & $\sqrt{ }$ & $\sqrt{ }$ \\
\hline $\begin{array}{l}\text { Technical } \\
\text { problems }\end{array}$ & $\sqrt{ }$ & $\sqrt{ }$ & $\sqrt{ }$ \\
\hline $\begin{array}{l}\text { User friendly } \\
\text { app }\end{array}$ & $\sqrt{ }$ & $\sqrt{ }$ & $\sqrt{ }$ \\
\hline ipad version & $\sqrt{ }$ & $\sqrt{ }$ \\
\hline $\begin{array}{l}\text { Export/Import } \\
\text { data }\end{array}$ & $\mathrm{x}$ & $\sqrt{ }$ & $\sqrt{ }$ \\
\hline $\begin{array}{l}\text { Support multiple } \\
\text { health providers }\end{array}$ & $\mathrm{x}$ & $\mathrm{x}$ \\
\hline $\begin{array}{l}\text { Technical } \\
\text { support }\end{array}$ & $\mathrm{V}$ & $\sqrt{ }$ \\
\hline Billing issues & $x$ & & $\sqrt{ }$ \\
\hline
\end{tabular}

\section{Conclusion}

As healthcare providers transition to population health management, they have recognized that engaging patients is essential to success. So far, they have largely relied on basic patient portals to do this. These basic, single-source portals do little to actually engage patients in their care. Next-generation patient portals are going to be needed to gain the attention of patients and move toward effective population health management.

Results indicate MyChart implementations burden the user with requiring different registrations, access requirements and user interfaces for each provider and patient (i.e., each provider has its own my chart system and you need to create a login for each). In order to improve the patient care experience, which is one of the triple aims goals, there is need to be a 'single source technology solution' to patient portals enabling users to access all their information in one presentation. Engaging patients and integrating their health data from multiple sources will enable them to contribute to their health maintenance and then help achieve the triple aim goals of improving the health of a population at a reduced costs. Results also reported consistent participation from treatment providers and being proactive in keeping all the My Chart information updated is an essential piece of the equation to improve the quality of the healthcare provided.

Chronic conditions require monitoring and intervention before health deteriorates. Improved communications with health providers, integration with health apps, giving patients full access to their records and health information such as lab results, prescription, and patient's information, providing patients with medical summaries of all their health issues as well as allowing patients to correct/update medical data such as vaccines will enable patients to take responsibility for their care, keep patients as healthy as possible (i.e., improving the health of the population) and minimize healthcare expenditures which will assist with achieving key goals of triple aim.

Transformative health technologies are innovations that fundamentally change care, (including self-care), and care delivery in ways that add substantial value to individuals and society [8]. For patient portals to gain this type of power, they will need the enhanced functionality identified by the patients and users of the technology. Multiple stakeholders including patients, providers, government and others will play key roles in developing Personal Health Records (PHRs) technology to overcome the barriers to fully enable PHRs to support population health and assist in achieving the goals of healthcare's triple aim. This research contributes the patient perspective for consideration to the vision of future PHR development and increased usage. When PHRs allow iterative communication between patients and health providers, notify patients regarding health issues, export data to and import data from other information systems, allow patients to schedule and track appointments, integrate patients with health apps, and transform clinical measurements and observations into meaningful and actionable information, fundamental changes in health technology usage, health care delivery and self-care by patients are possible.

\section{References}


[1] CDCP. (2013, The State of Aging and Health in America 2013. Available: https://www.cdc.gov/aging/pdf/state-aging-health-inamerica-2013.pdf

[2] N. Yaraghi, The benefits of health information exchange platforms: measuring the returns on a half a billion dollar investment: Center for Technology Innovation at Brookings, 2015.

[3] K. Davis, K. Stremikis, D. Squires, and C. Schoen, "Mirror, mirror on the wall, 2014 update: how the US health care system compares internationally," The Commonwealth Fund, pp. 1-31, 2014.

[4] D. Kindig and G. Stoddart, "What is population health?," American journal of public health, vol. 93, pp. 380-383, 2003.

[5] CDW. (2016, Patient Engagement Perspectives Key Findings. Available: http://www.cdwnewsroom.com/wpcontent/uploads/2016/02/Patient-Engagement-PerspectivesKey-Findings_022316a-FINAL.pdf

[6] E. Agu, P. Pedersen, D. Strong, B. Tulu, Q. He, L. Wang, et al., "The smartphone as a medical device: Assessing enablers, benefits and challenges," in Sensor, Mesh and Ad Hoc Communications and Networks (SECON), 2013 10th Annual IEEE Communications Society Conference on, 2013, pp. 76-80.

[7] E. V. Wilson, Patient-centered e-health. Hershey, PA: IGI Global, 2008.

[8] D. Detmer, M. Bloomrosen, B. Raymond, and P. Tang, "Integrated personal health records: transformative tools for consumer-centric care," BMC medical informatics and decision making, vol. 8, p. 45, 2008.

[9] M. Prgomet, A. Georgiou, and J. I. Westbrook, "The impact of mobile handheld technology on hospital physicians' work practices and patient care: a systematic review," Journal of the American Medical Informatics Association, vol. 16, pp. 792-801, 2009.

[10] G. L. Gaskin, C. A. Longhurst, R. Slayton, and A. K. Das, "Sociotechnical challenges of developing an interoperable personal health record: lessons learned," Appl Clin Inform, vol. 2, pp. 406-419, 2011.

[11] J. Sarasohn-Kahn. (2017, Patients grow comfortable with digital health tools, CDW finds both your and old are using healthcare portals.

[12] HIMSS. (2015) Mobile tech is key to patient engagement. Health Management Technology.

[13] D. Halo, "Patients Grow Comfortable With Digital Health Tools, CDW Finds," Health IT News Feed2017.
[14] S. Djamasbi, W. Li, M. Traietti, L. C. T. Tran, V. Valcour, J. Wyatt, et al., "Web Experience and Growth," 2015.

[15] V. Wilson and S. Djamasbi, "Human-computer interaction in health and wellness: Research and publication opportunities," AIS Transactions on HumanComputer Interaction, vol. 7, pp. 97-108, 2015.

[16] S. Qureshi and P. Keen, "Activating knowledge through electronic collaboration: Vanquishing the knowledge paradox," IEEE Transactions on Professional Communication, vol. 48, pp. 40-54, 2005.

[17] S. Qureshi, M. Liu, and D. Vogel, "A grounded theory analysis of e-collaboration effects for distributed project management," in System Sciences, 2005. HICSS'05. Proceedings of the 38th Annual Hawaii International Conference on, 2005, pp. 264c-264c.

[18] S. Qureshi and C. Noteboom, "Adaptation in distributed projects: Collaborative processes in digital natives and digital immigrants," in System Sciences, 2006. HICSS'06. Proceedings of the 39th Annual Hawaii International Conference on, 2006, pp. 202c-202c.

[19] J. A. Chevalier and D. Mayzlin, "The effect of word of mouth on sales: Online book reviews," Journal of marketing research, vol. 43, pp. 345-354, 2006.

[20] J. Yang, R. Sarathy, and J. Lee, "The effect of product review balance and volume on online Shoppers' risk perception and purchase intention," Decision Support Systems, vol. 89, pp. 66-76, 2016.

[21] R. Koppel and C. U. Lehmann, "Implications of an emerging EHR monoculture for hospitals and healthcare systems," Journal of the American Medical Informatics Association, pp. amiajnl-2014-003023, 2014.

[22] M. A. Al-Ramahi, J. Liu, and O. F. El-Gayar, "Discovering Design Principles for Health Behavioral Change Support Systems: A Text Mining Approach," ACM Transactions on Management Information Systems (TMIS), vol. 8, 2017.

[23] J. M. García-Gómez, I. de la Torre-Díez, J. Vicente, M. Robles, M. López-Coronado, and J. J. Rodrigues, "Analysis of mobile health applications for a broad spectrum of consumers: a user experience approach," Health informatics journal, vol. 20, pp. 74-84, 2014.

[24] L. Guerra-Reyes, V. M. Christie, A. Prabhakar, A. L. Harris, and K. A. Siek, "Postpartum Health Information Seeking Using Mobile Phones: Experiences of LowIncome Mothers," Maternal and Child Health Journal, vol. 20, pp. 13-21, 2016.

[25] M. W. Zhang, R. Ho, S. E. Cassin, R. Hawa, and S. Sockalingam, "Online and smartphone based cognitive behavioral therapy for bariatric surgery patients: Initial 
pilot study," Technology and Health Care, vol. 23, pp. 737744, 2015.

[26] S. Moore and D. Jayewardene, "The use of smartphones in clinical practice: Sally Moore and Dharshana Jayewardene look at the rise in the use of mobile software at work," Nursing Management, vol. 21, pp. 18-22, 2014.

[27] X. Liang, Q. Wang, X. Yang, J. Cao, J. Chen, X. Mo, et al., "Effect of mobile phone intervention for diabetes on glycaemic control: a meta-analysis," Diabetic medicine, vol. 28 , pp. 455-463, 2011.

[28] B. B. Green, A. J. Cook, J. D. Ralston, P. A. Fishman, S. L. Catz, J. Carlson, et al., "Effectiveness of home blood pressure monitoring, Web communication, and pharmacist care on hypertension control: a randomized controlled trial," Jama, vol. 299, pp. 2857-2867, 2008.

[29] A. G. Logan, M. J. Irvine, W. J. McIsaac, A. Tisler, P. G. Rossos, A. Easty, et al., "Effect of Home Blood Pressure Telemonitoring With Self-Care Support on Uncontrolled Systolic Hypertension in DiabeticsNovelty and Significance," Hypertension, vol. 60, pp. 51-57, 2012.

[30] N. Shah, J. Jonassaint, and L. De Castro, "Patients welcome the sickle cell disease mobile application to record symptoms via technology (SMART)," Hemoglobin, vol. 38, pp. 99-103, 2014.

[31] M. I. Stuckey, S. Shapiro, D. P. Gill, and R. J. Petrella, "A lifestyle intervention supported by mobile health technologies to improve the cardiometabolic risk profile of individuals at risk for cardiovascular disease and type 2 diabetes: study rationale and protocol," BMC public health, vol. 13, p. 1051, 2013.

[32] G. Lee, J. Y. Park, S.-Y. Shin, J. S. Hwang, H. J. Ryu, J. H. Lee, et al., "Which users should be the focus of mobile personal health records? Analysis of user characteristics influencing usage of a tethered mobile personal health record," Telemedicine and e-Health, vol. 22, pp. 419-428, 2016.

[33] K. J. O’Leary, R. K. Sharma, A. Killarney, L. S. O'Hara, M. E. Lohman, E. Culver, et al., "Patients' and healthcare providers' perceptions of a mobile portal application for hospitalized patients," BMC Medical Informatics and Decision Making, vol. 16, p. 123, 2016.

[34] L. Pfeifer Vardoulakis, A. Karlson, D. Morris, G. Smith, J. Gatewood, and D. Tan, "Using mobile phones to present medical information to hospital patients," in Proceedings of the SIGCHI Conference on Human Factors in Computing Systems, 2012, pp. 1411-1420.

[35] P. C. Dykes, D. L. Carroll, A. C. Hurley, A. Benoit, F. Chang, R. Pozzar, et al., "Building and testing a patientcentric electronic bedside communication center," Journal of gerontological nursing, 2012.
[36] A. S. McAlearney, C. J. Sieck, J. L. Hefner, A. M. Aldrich, D. M. Walker, M. K. Rizer, et al., "High Touch and High Tech (HT2) Proposal: Transforming Patient Engagement Throughout the Continuum of Care by Engaging Patients with Portal Technology at the Bedside," JMIR Research Protocols, vol. 5, 2016.

[37] Y.-H. Lu, L.-Y. Lee, Y.-L. Chen, H.-I. Cheng, W.-T. Tsai, C.-C. Kuo, et al., "Developing an App by Exploiting Web-Based Mobile Technology to Inspect Controlled Substances in Patient Care Units," BioMed Research International, vol. 2017, 2017.

[38] P. Pierleoni, L. Pernini, A. Belli, and L. Palma, "An android-based heart monitoring system for the elderly and for patients with heart disease," International journal of telemedicine and applications, vol. 2014, p. 10, 2014.

[39] L. Neubeck, G. Coorey, D. Peiris, J. Mulley, E. Heeley, F. Hersch, et al., "Development of an integrated ehealth tool for people with, or at high risk of, cardiovascular disease: The Consumer Navigation of Electronic Cardiovascular Tools (CONNECT) web application," International journal of medical informatics, vol. 96, pp. 24-37, 2016.

[40] E. Haddi, X. Liu, and Y. Shi, "The role of text preprocessing in sentiment analysis," Procedia Computer Science, vol. 17, pp. 26-32, 2013.

[41] D. M. Blei, A. Y. Ng, and M. I. Jordan, "Latent dirichlet allocation," the Journal of machine Learning research, vol. 3, pp. 993-1022, 2003.

[42] Y. Bao and A. Datta, "Simultaneously discovering and quantifying risk types from textual risk disclosures," Management Science, vol. 60, pp. 1371-1391, 2014. 